\title{
The Importance of Postural Control in Relation to Technical Abilities in Small-Sided Soccer Games
}

\author{
by \\ Çağlar Edis ${ }^{1}$, Faik Vural ${ }^{2}$, Hikmet Vurgun
}

\begin{abstract}
Making assessments regarding postural control and balance is very important for injury prevention in soccer. However, there has been no study that has associated postural control variables with branch-specific technical properties in a game. The aim of the present study was to determine the relationships between variables designating postural control levels and technical performance variables in different (1:1,2:2 and 3:3) small-sided games (SSGs). Sixteen trained male amateur soccer players volunteered to take part in the study (age $17.2 \pm 1.02$ years, body height $176.25 \pm$ $0.07 \mathrm{~m}$, body mass $67.67 \pm 13.27 \mathrm{~kg}$ ). Following familiarization sessions, postural control was evaluated using one-leg and both-leg quiet-stance positions by measuring postural sway with a Tekscan HR Mat ${ }^{\mathrm{TM}}$ in anterior-posterior and medial-lateral directions. Later, 1:1, 2:2 and 3:3 SSGs were performed at two-day intervals and the technical variables specified for each game were analyzed. A Spearman's rank-order correlation analysis demonstrated the relationship between postural control and soccer-specific technical variables in 1:1 (r-values ranging from 0.582 to 0.776), 2:2 ( $r$ values ranging from 0.511 to 0.740 ) and 3:3 (r-values ranging from 0.502 to 0.834) SSGs. In addition, a Wilcoxon signed rank test revealed differences between SSGs in terms of several variables. The results of the study showed that higher postural control levels are among the important variables that affect success in the performance of technical skills under rival pressure and suddenly changing conditions. Therefore, it is recommended that in addition to its use for injury prevention purposes, balance training should be conducted to improve branch-specific technical skills and to increase the levels of their successful performance in a game.
\end{abstract}

Key words: balance, soccer, technical actions, pedobarography.

\section{Introduction}

The ability to perform several motor features such as endurance, speed, strength, balance and quickness, together in soccer, is critically important in determining match performance (winning-losing). In addition, during physical tackling in contact with the opponent, the performance of soccer-specific skills such as passing, shooting and dribbling, is one of the variables that directly affect match scores (Hughes and Franks, 2005). Using these skills together promotes improvement of the variables that are encountered during a match and they may be

affected by having various skill levels. Smallsided games (SSGs) have similar properties to soccer matches, although the number of players and game targets may differ. Practices that use different pitch sizes and different areas of the pitch (Katis and Kellis, 2009) are frequently used for training to support the athletes' combined physical and technical development (Casamichana and Castellano, 2010; Jones and Drust, 2007; Köklü et al., 2011). In the literature, small-sided games have been examined in detail, both in terms of the effects of factors such as pitch

1 - Ege University, Institute of Medical Sciences, Bornova-Izmir, Turkey.

2 - Ege University, Faculty of Sport Sciences, Bornova-Izmir, Turkey.

3 - Celal Bayar University, School of Physical Education and Sport, Manisa, Turkey. 
size, the number of players, target differences and game times on the physiological performance of players and performance variables such as the number of contacts with the ball, running distances, speed and movement analyses (Casamichana and Castellano, 2010; Castellano et al., 2013; Hill-Haas et al., 2009; Kelly and Drust, 2009). Most of the research has confirmed that SSGs have an important effect on performance development such as aerobic capacity, the ability to perform high intensity actions and technical variables (Dellal et al., 2012b; Katis and Kellis, 2009). However, SSGs may not be a sufficient training method for performance development, especially considering that Dellal et al. (2012a) showed that the physiological responses to SSGs were dependent on the skill levels of the players. Therefore, according to the skill level of the players, different results could be obtained.

Regardless of the player's level, performance of branch-specific technical movements (shooting, passing, etc.) that depend on complex motor skills during a match requires good balance perception and, in particular, good posture when standing on one leg. Posture, which defines the body position that is maintained with myotatic reflexes and opposes gravity, provides the mechanical support needed to perform a movement with an antigravity function in the first place. Secondly, it forms a reference framework to organize the movement to be performed (Jeannerod, 1988; Paillard, 1991). Thus, postural functions that is very important for the performance of movements must also be maintained during movement (Massion, 1998). These explanations may suggest that branches of different movement patterns in sports could have different postural performances and strategies and that they may differ in terms of the levels at which they affect these features. Numerous studies carried out on individual sports have examined the use of visual contributions and postural conditions (unipedal, bipedal, handout) (Vuillerme al., 2001a), which may cause differences in postural control and vary by sporting experience (Vuillerme et al., 2001b), such as whether the person is an athlete or non-athlete and the status of the athlete (elite or amateur) (Davlin, 2004; Paillard et al., 2002). While results concerning the differences obtained have varied statistically among studies, it has been stated that training and competitive experience of an athlete may influence these results.

Unlike other individual and team sports, in soccer, movements of a unipedal form such as hiding the ball from the opponent with one foot while struggling at the same time with sudden shooting/passing are used. In movements of this form, players seem to have better results than dancers who intensively use a unipedal stance in terms of some postural performance features (Gerbino et al., 2007). To determine the importance of balance in soccer, Paillard et al. (2006) studied postural performance in single foot stances of players at different levels (national or regional). They reported that national players showed better performance than regional ones probably owing to sensory receptors of greater sensitivity and better information integration. In addition, visual contributions seem to be important as well as a unipedal stance in the maintenance of postural performance. This is because a high level of visual information is required to control the ball together with assessing the movements of opponents and teammates simultaneously, and visual information may, in turn, be significant in maintaining posture. Paillard and Noe (2006) also suggested that the need for visual information in the maintenance of posture varies between amateur and professional soccer players. The results they obtained concerning this hypothesis showed that since professional players developed their ability to perform movements with the ball while looking at the ball less frequently, they needed visual data for postural control less than amateur players did. The majority of other studies carried out on this topic appear to have aimed at preventing players' risk of lower extremity injuries and examined the effects of training for rehabilitation purposes (Gauffin et al., 1988; Pintsaar et al., 1996; Soderman et al., 2000).

In conclusion, the idea behind previous studies was to determine the different effects of sports branches that have different movement patterns and differences in player levels on postural control performance. Contrary to these studies, it would be more interesting to evaluate the interactions of the characteristics of postural control with the technical performances that are specific to a particular branch of sports.

In this respect, the aim of the present 
study was to examine the relationships between variables of postural control characteristics of players and their ability to perform soccer specific skills during SSGs played with various numbers of players. It was hypothesized that players who had better postural control levels (postural swing speed, a right-left postural swing and a front-back postural swing) during unipedal and bipedal stances (eyes open and eyes closed) would perform soccer-specific technical skills at a higher level.

\section{Material and Methods}

\section{Participants and Procedures}

Sixteen amateur soccer players participated voluntarily in the study (age 17.2 \pm 1.02 years, body height $176.25 \pm 0.07 \mathrm{~m}$, body mass $67.67 \pm$ $13.27 \mathrm{~kg}$ ). Two of the participants were excluded from the study because of a lack of compliance with testing procedures and health problems. Thus, the data evaluated were collected from 16 athletes who completed all tests successfully. They had been training for at least 6 years $(4$ training sessions $[2 \pm 0.5 \mathrm{~h}$ per training] and 1 official match per week). The study was designed according to the rules and principles of the Declaration of Helsinki and approved by the University Ethics Committee (EGE.ETK. 15/02/2014, 20478486-70). Written informed consent was obtained after an explanation of the nature and risks involved in participation in the experiment.

On a predetermined day prior to the tests to be applied in the study, the athletes and their guardians were informed about the topic, purpose, possible risks and benefits of the study. Voluntary consent forms were read and signed by the athletes and their guardians (for athletes under 18 years old). On the same day, a familiarization session was held and each athlete performed two sets of each movement included in the procedures to be applied for the athletes' adaptation to postural control test procedures in the study. On the day after recovery-oriented training, athletes' body height and mass were measured and skinfold measurements were taken to determine body composition. Upon completion of these measurements, postural control tests were initiated. One week later, these measurements (every other day following recovery training) and 1:1, 2:2 and 3:3 small sided games were performed.

\section{Anthropometric Measurements}

Body mass and height of the athletes were measured barefoot while wearing shorts. Body fat ratios were determined with a Harpender caliper using the skinfold method in which the thickness of skinfolds from certain parts of the right side of the body was measured (Holtain Ltd., UK). The skinfold measurements were taken from 7 parts of the body, namely the triceps, subscapular, axilla, chest, suprailiac, abdomen and thigh. All anthropometric measurements were taken by the same researcher. Estimated body density was calculated using the equation developed by Durnin and Rahaman (1967) for men. The data obtained from this equation were used in an equation determining body composition for each athlete (Siri, 1956).

\section{Postural Control Test Protocols}

Prior to the test, the athletes participated in the injury preventive "HarmoKnee" exercise procedure, which was a planned warm-up program that placed less force on knee joints (Daneshjoo et al., 2012). Postural control was calculated using the center of pressure (CoP) deviations in anterior- posterior (ap) and mediallateral $(\mathrm{ml})$ directions while standing on one leg or two legs. To obtain a quantitative description of postural control, the following $\mathrm{CoP}$ variables were computed: a dominant (d) and non-dominant (nd) leg; anterior-posterior sway ( $\mathrm{CoP}_{\text {dap }}$ and $\left.\mathrm{CoP}_{\text {ndap }}\right)$; medial-lateral sway ( $\mathrm{CoPdml}$ and $\mathrm{CoP}$ ndml); sway velocity ( $\mathrm{CoP}$ dvel) and sway average (CoPdvar); both-feet, eyes-closed, right-left postural sway (CoPecml); both-feet, eyes-closed, right-left postural sway velocity (CoPecvel) and sway average (CoPecvar). Postural sway measurements were taken with a HR Mat (TekScan Inc, South Boston, MA, USA) pedobarography device (area of perception $487.7 \times 447.0 \mathrm{~mm}$, 4 sensors per $\mathrm{cm}^{2}$, pressure rate $862 \mathrm{kPa}$ and mat height $0.57 \mathrm{~cm}$ ). The procedure for calibration was conducted according to the manufacturer's directions prior to each measurement. One practice trial was allowed before the beginning of data collection; all subjects were tested barefoot. Foot standing positions for both feet were standardized on an HR Mat according to the pre-designed scheme to arrange an intermalleolar distance at $5 \mathrm{~cm}$ and feet opening angle of $30^{\circ}$. The same scheme was used for one foot posture, and while the dominant 
foot was on the mat, the other foot was bent $90^{\circ}$ from the knee and standardized with the sole pointing to the back and tibia parallel to the ground (Gerbino et al., 2007). The dominant leg was defined by asking the person which leg they used to kick a ball (13 were right-legged and 3 were left-legged). The participants were told to stand upright while looking at the visual target placed at eye level $2 \mathrm{~m}$ in the distance, and measurements were started $5 \mathrm{~s}$ after the subject said they were ready. Measurements were taken twice and each lasted $30 \mathrm{~s}$, with 3 min rest periods between repeated measures for each posture position, both with eyes open (eo) and eyes closed (ec). Data from the measurements were recorded as 1,500 points in total with a $50 \mathrm{~Hz}$ frequency. Sway Analysis Module $\left(\mathrm{SAM}^{\mathrm{TM}}\right)$ software was used to analyze the data.

As an important note, values for postural control variables calculated from the $\mathrm{CoP}$ deviations that were lower indicate that postural control was better.

\section{Small-Sided Games}

Small sided games took place in 3 different formats in which official competition rules were used and the number of players differed. For 1:1, 2:2 and 3:3 games, pitch sizes described in the literature and methods of practice (game times, rest periods, the number of repetitions) that are commonly used for these games were utilized (Dellal et al., 2012b; Hill-Haas et al., 2009). In this respect, games 1:1, 2:2 and 3:3 were played on pitches of $15 \times 10 \mathrm{~m}=150 \mathrm{~m}^{2}\left(1: 38 \mathrm{~m}^{2}\right.$ pitch ratio per player), $18 \times 24 \mathrm{~m}=432 \mathrm{~m}^{2}\left(1: 72 \mathrm{~m}^{2}\right.$ pitch ratio per player), $30 \times 40 \mathrm{~m}=1,200 \mathrm{~m}^{2}\left(1: 150 \mathrm{~m}^{2}\right.$ pitch ratio per player), for $4 \times 1 \mathrm{~min}, 4 \times 2 \mathrm{~min}, 4 \times 3 \mathrm{~min}$ and with 1,2 and 3 min recovery periods between games, respectively.

\section{Technical Analysis of SSG}

Three different small-sided games with a total of 12 games were filmed for the entire duration of the SSG using a video camera (Sony Handycam, DCR-SR15) to analyze the technical actions. The matches were watched again using the MUNA Match Analysis Program (MUNA Analiz, 2006) on the same computer and each game was analyzed by marking and collecting data with the notation match analysis method using the match analysis program. The following technical variables were considered: successful tackle $\left(\mathrm{T}_{\mathrm{s}}\right)$, unsuccessful tackle $\left(\mathrm{T}_{\mathrm{us}}\right)$, successful dribbling past $\left(\mathrm{DP}_{\mathrm{s}}\right)$, unsuccessful dribbling past (DPus), successful shot ( $\left.\mathrm{S}_{\mathrm{s}}\right)$, unsuccessful shot (Sus), successful sliding tackle $\left(\mathrm{ST}_{\mathrm{s}}\right)$, and unsuccessful sliding tackle (STus) for (a) 1:1 games. For (b) 2:2 and 3:3 games; variables of successful pass $\left(\mathrm{P}_{\mathrm{s}}\right)$, unsuccessful pass ( $\mathrm{P}_{\mathrm{us}}$ ) and assist were added to the technical variables used in 1:1 games.

\section{Statistical Analyses}

The data were tested for normal distribution using the Shapiro-Wilk test. Since the data did not comply with the assumption of a normal distribution, non-parametric analysis methods were employed and data were reported as medians. In addition, a Friedman's test was used for repeated dependent variables (HR, technical variables) in 3 different SSGs. When the results of this test were significant, pairwise comparisons were performed for the HR and technical variables in 1:1, 2:2 and 3:3 games by the Wilcoxon's signed rank test. Levels of the relationship between postural control levels and SSG football technical variables (successful passes, sliding tackles, shots, winning and losing the ball in tackles, etc.) were examined using Spearman rank-order correlation analysis. All the statistical analyses were performed using SPSS 20.0 for Windows (SPSS Inc., Chicago, IL, USA). The level of significance was set at $p<0.05$.

\section{Results}

After the performance of 12 exercises in 3 different SSGs, a Friedman's test was run to determine if there were differences in the HR. Pairwise comparisons were performed for multiple comparisons (Figure 1). The HR was statistically significantly different for the 3 types of SSGs during the exercise, $\left(\chi^{2}[2]=5.746 ; p<.05\right)$.

Sixteen participants were recruited to analyze the effect of soccer technical performances of different numbers of players on game performance as measured by the technical analysis. Table 1 shows Friedman's test results, and the data are shown as medians. A Wilcoxon signed-rank test determined that there was a statistically significant median decrease in successful shots $\left(\mathrm{S}_{\mathrm{s}}\right)$ when 1:1 games were compared with 2:2 $(\mathrm{Mdn}=4.50, \mathrm{z}=-2.282, p=$ $0.022)$ and 3:3 (Mdn $=4.50, \mathrm{z}=-2.537, p=0.011)$ games. Moreover, significant decreases in median values were found for the unsuccessful dribbling past (DPus) variable between 1:1 and 2:2 SSGs 
$(\mathrm{Mdn}=1.50, \mathrm{z}=-2,777, p=0.005)$, the successful pass $\left(P_{s}\right)$ variable between 2:2 and 3:3 SSGs (Mdn $=6.50, \mathrm{z}=-3.301, p=0.001)$, and for the $\mathrm{T}_{\mathrm{s}}$ variable between 1:1 and 2:2 $(\mathrm{Mdn}=1.50, \mathrm{z}=-2,448, p=$ 0.014 ) and 1:1 and 3:3 SSGs (Mdn $=1.50, z=-2,018$, $p=0.044)$.

Table 2 shows the results of the Spearman's rank-order correlation analysis, demonstrating the relationship between postural control (a dominant leg, eyes closed using both legs) and soccer specific technical variables in the 1:1 SSG. Significant relationships were found between the postural variables of the dominant-leg and eyesclosed test using both legs and technical performance variables ( $\mathrm{r}$-values ranging from 0.522 to 0.776 ), whereas it was seen that only postural sway velocity ( $\mathrm{CoP}$ eovel) had a significant relationship with successful dribbling past $(\mathrm{r}=$ 0.552, $p<0.05)$. However, no significant correlation was found between the non-dominant leg and technical variables $(p>0.05)$.

Postural control variables (a dominant leg, eyes closed using both legs), except $\mathrm{CoP}_{\text {dap }}, \mathrm{CoP}_{d m l}$, CoPdvel, CoPdvar, $\mathrm{CoPecml,} \mathrm{CoP}$ ecvel, $\mathrm{CoP}$ ecvar, were significantly correlated with tackle (successful, unsuccessful), dribble past (unsuccessful), pass (successful) and assist (successful) variables for the 2:2 SSG, with r-values ranging from 0.511 to 0.740 (Table 3). However, other soccer specific technical variables, i.e., sliding tackle and shot, did not significantly correlate with postural control measures for the 2:2 SSG, with r-values ranging from 0.044 to 0.410 (Table 3 ). In addition, a negative correlation was found between the $\mathrm{CoP}_{\mathrm{ml}}$ variable for the non-dominant leg and total successful shots $(\mathrm{r}=-0.575, p<0.05)$. During standing on both legs with eyes open, there was no correlation between any of the CoP variables and technical variables ( $\mathrm{r}$-values ranging from 0.002 to 0.490 ).

The correlations between the technical variables of the 3:3 SSG and CoPdap, CoPdml, CoPvel, CoPvar, $\mathrm{CoP}$ ecml, CoPecvel, $\mathrm{CoP}$ ecvar are illustrated in Table 4. Significant correlations were found between technical variables except dribble past and postural control variables with r-values ranging from 0.502 to 0.834 (Table 4). Among the other postural control variables, a negative correlation was found between the non-dominant leg $\mathrm{CoP}_{\mathrm{ml}}$ variable and total unsuccessful passes ( $\mathrm{r}$ $=-0.588, p<0.05)$. In contrast, no significant relationship was found between the technical performance variables and other postural control variables of the non-dominant leg and both legs with the eyes-open position (r-values ranging from 0.013 to 0.467 and 0.007 to 0.451 , respectively).

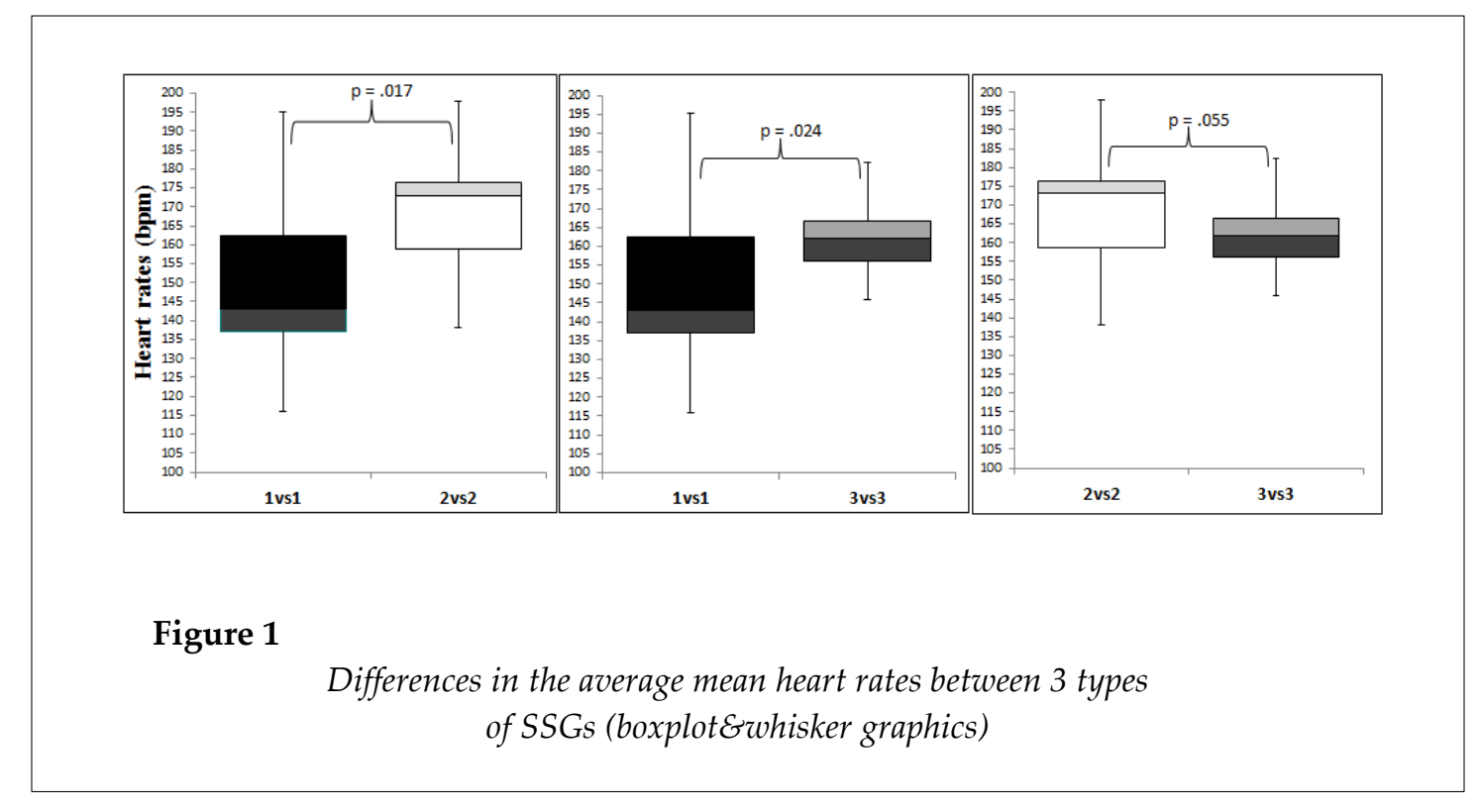


Table 1

Differences in the soccer technical variables during 3 types of SSGs

\begin{tabular}{|c|c|c|c|c|c|c|c|c|c|c|c|}
\hline & & 1:1 Game & & & 2:2 Game & & & 3:3 Gam & & & \\
\hline & 25 th & Median & 75th & 25th & Median & 75th & 25th & Median & 75th & $\chi^{2}$ & PFriedman \\
\hline $\mathrm{T}_{\mathrm{s}}$ & 0.00 & 2.50 & 4.00 & 0.00 & 1.00 & 2.00 & 0.00 & 1.00 & 1.00 & 0.286 & 0.867 \\
\hline Tus & 0.00 & $2.50^{\mathrm{ef}}$ & 4.00 & 0.00 & $1.00^{\mathrm{e}}$ & 2.00 & 0.00 & $1.00^{\mathrm{f}}$ & 2.00 & 6.513 & $0.039^{*}$ \\
\hline $\mathrm{ST}_{\mathrm{s}}$ & 0.00 & 1.50 & 3.75 & 0.25 & 1.00 & 2.00 & 0.00 & 0.50 & 1.00 & 5.673 & 0.059 \\
\hline $\mathrm{ST}_{\text {us }}$ & 0.00 & 0.00 & 0.75 & 0.00 & 0.00 & 0.00 & 0.00 & 0.00 & 0.00 & 1.143 & 0.565 \\
\hline $\mathrm{S}_{\mathrm{s}}$ & 3.00 & $7.50^{\mathrm{ab}}$ & 9.00 & 3.00 & $3.00^{\mathrm{a}}$ & 5.00 & 2.25 & $3.00^{\mathrm{b}}$ & 4.00 & 6.295 & $0.043^{*}$ \\
\hline Sus & 0.00 & 0.00 & 1.00 & 0.00 & 1.00 & 1.75 & 0.25 & 1.00 & 2.00 & 5.647 & 0.059 \\
\hline $\mathrm{DP}_{\mathrm{s}}$ & 1.00 & 2.50 & 3.75 & 0.25 & 2.00 & 3.00 & 0.00 & 1.50 & 3.75 & 1.750 & 0.417 \\
\hline $\mathrm{DPus}$ & 1.00 & $2.00^{c}$ & 4.75 & 0.00 & $0.50^{c}$ & 1.75 & 0.00 & 1.00 & 1.75 & 6.962 & $0.031^{*}$ \\
\hline $\mathrm{P}_{\mathrm{s}}$ & - & - & - & 3.50 & $7.00^{\mathrm{d}}$ & 7.75 & 8.00 & $13.50^{\mathrm{d}}$ & 17.00 & 14.00 & $0.000^{* *}$ \\
\hline Pus & - & - & - & 1.00 & 2.00 & 3.75 & 2.00 & 3.00 & 3.00 & 0.067 & 0.796 \\
\hline Assist & - & - & - & 0.25 & 1.00 & 2.75 & 0.25 & 1.50 & 3.00 & 0.333 & 0.564 \\
\hline
\end{tabular}

$" p<0.05, " * p<0.005, a, b, c, d, e$, statistically significant decrease in median in the Wilcoxon signed-rank test between

SSG, Ts: successful tackle, Tus: unsuccessful tackle,

STs: successful sliding tackle, STus: unsuccessful

sliding tackle, Ss: successful shooting, Sus: unsuccessful shooting, $D P_{s}$ : successful dribbling past, $D P_{u s:}$ unsuccessful dribbling past, $P_{s}$ : successful pass, $P_{u s:}$ unsuccessful pass

Table 2

1:1 Correlation coefficients between SSG soccer technical analysis data $\mathrm{CoP}_{d}$ and $\mathrm{CoP}_{e c}$ levels

\begin{tabular}{|c|c|c|c|c|c|c|c|c|}
\hline & & $\frac{\frac{2}{\pi}}{0}$ & 吾 & $\tilde{0}_{0}^{\vec{D}}$ & 总 & 胥 & 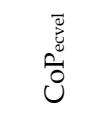 & 蒡 \\
\hline \multirow{2}{*}{ Tackle } & Successful & -0.34 & $-0.59^{*}$ & -0.40 & $-0.58^{*}$ & -0.42 & $-0.67^{* *}$ & $-0.72^{* *}$ \\
\hline & Unsuccessful & 0.33 & 0.42 & 0.37 & $0.52^{*}$ & 0.27 & 0.46 & $0.77^{* *}$ \\
\hline \multirow{2}{*}{$\begin{array}{l}\text { Sliding } \\
\text { Tackle }\end{array}$} & Successful & -0.25 & -0.16 & -0.34 & -0.22 & -0.11 & 0.13 & -0.01 \\
\hline & Unsuccessful & 0.30 & 0.18 & 0.09 & 0.18 & 0.40 & 0.41 & 0.20 \\
\hline \multirow{2}{*}{ Shot } & Successful & -0.09 & -0.30 & -0.33 & -0.27 & -0.39 & -0.18 & $-0.62^{* *}$ \\
\hline & Unsuccessful & -0.10 & 0.20 & 0.11 & 0.17 & -0.19 & -0.18 & -0.29 \\
\hline \multirow{2}{*}{$\begin{array}{l}\text { Dribble } \\
\text { past }\end{array}$} & Successful & -0.10 & -0.24 & $-0.58^{*}$ & -0.45 & $-0.60^{*}$ & -0.24 & $-0.55^{*}$ \\
\hline & Unsuccessful & -0.14 & 0.04 & -0.01 & -0.09 & 0.35 & 0.41 & 0.46 \\
\hline
\end{tabular}

${ }^{*} p<0.05,{ }^{* *} p<0.01, C o P_{\text {dap }}$ : dominant leg anterior-posterior sway, CoPdml: dominant leg medial-lateral sway, CoPdvel: dominant leg sway velocity, CoPdvar: dominant leg sway velocity average, CoPecml: both leg stance eyes closed medial-lateral sway, CoPecvel: both leg stance eyes closed sway velocity, CoPecuar: both, leg stance eyes closed sway velocity average. 
Table 3

2:2 Correlation coefficients between SSG soccer technical analysis data and $\mathrm{CoP}_{d}$ and $\mathrm{CoP}_{e c}$ levels

\begin{tabular}{|c|c|c|c|c|c|c|c|c|}
\hline & & CoPdap & $\mathrm{CoPdml}$ & $\mathrm{CoP}_{\text {vel }}$ & $\mathrm{CoP}_{\text {var }}$ & CoPecml & CoPecvel & CoPecvar \\
\hline \multirow{2}{*}{ Tackle } & Successful & -0.24 & -0.18 & $-0.74^{* *}$ & $-0.51^{*}$ & $-0.67^{* *}$ & -0.49 & $-0.69^{* *}$ \\
\hline & Unsuccessful & 0.37 & $0.54^{*}$ & 0.18 & 0.41 & 0.11 & -0.05 & 0.23 \\
\hline \multirow{2}{*}{$\begin{array}{l}\text { Sliding } \\
\text { Tackle }\end{array}$} & Successful & -0.33 & -0.11 & -0.07 & -0.05 & -0.17 & -0.23 & -0.16 \\
\hline & Unsuccessful & -0.15 & 0.20 & -0.24 & -0.41 & -0.32 & -0.20 & -0.12 \\
\hline \multirow{2}{*}{ Shot } & Successful & $0.52^{*}$ & 0.35 & -0.09 & 0.04 & -0.07 & -0.14 & -0.36 \\
\hline & Unsuccessful & 0.27 & 0.44 & 0.35 & 0.48 & 0.18 & -0.14 & -0.08 \\
\hline \multirow{2}{*}{$\begin{array}{l}\text { Dribble } \\
\text { Past }\end{array}$} & Successful & 0.39 & 0.07 & -0.17 & -0.19 & -0.07 & 0.05 & -0.48 \\
\hline & Unsuccessful & -0.10 & 0.08 & 0.13 & -0.27 & 0.34 & $0.60^{*}$ & 0.45 \\
\hline \multirow{2}{*}{ Passing } & Successful & -0.15 & -0.03 & -0.36 & -0.29 & -0.35 & -0.29 & $-0.55^{*}$ \\
\hline & Unsuccessful & 0.08 & 0.30 & -0.02 & 0.03 & -0.09 & -0.16 & -0.11 \\
\hline Assit & Successful & -0.03 & -0.23 & $-0.64^{* *}$ & $-0.53^{*}$ & -0.18 & -0.03 & -0.33 \\
\hline
\end{tabular}

${ }^{*} p<0.05,{ }^{* *} p<0.01, C o P_{d a p}$ : dominant leg anterior-posterior sway, CoPdml: dominant leg mediallateral sway, CoPdvel: dominant leg sway velocity, CoPdvar: dominant leg sway average, CoPecml: both leg stance eyes closed medial-lateral sway, CoPecvel: both leg stance eyes closed sway velocity, CoPecoar: both leg stance eyes closed sway average

\begin{tabular}{|c|c|c|c|c|c|c|c|c|}
\hline \multicolumn{9}{|c|}{$\begin{array}{l}\text { Table } 4 \\
\text { 3:3 Correlation coefficients between SSG soccer technical analysis data } \\
\text { and CoPd and CoPec levels }\end{array}$} \\
\hline \multirow{3}{*}{ Tackle } & & CoPdap & $\mathrm{CoPdml}$ & $\mathrm{CoP}_{\text {vel }}$ & $\mathrm{CoP}_{\text {var }}$ & CoPecml & CoPecvel & CoPecvar \\
\hline & Successful & -0.40 & $-0.72^{* *}$ & -0.31 & $-0.50^{*}$ & -0.26 & 0.11 & -0.26 \\
\hline & Unsuccessful & 0.45 & $0.53^{*}$ & $0.60^{*}$ & $0.67^{*}$ & 0.44 & -0.08 & 0.25 \\
\hline \multirow{2}{*}{$\begin{array}{l}\text { Sliding } \\
\text { Tackle }\end{array}$} & Successful & -0.31 & $-0.64^{* *}$ & -0.11 & -0.32 & -0.29 & -0.21 & -0.23 \\
\hline & Unsuccessful & 0.17 & 0.09 & 0.22 & 0.22 & 0.01 & -0.18 & 0.03 \\
\hline \multirow{2}{*}{ Shot } & Successful & 0.085 & -0.02 & -0.06 & 0.10 & -0.06 & 0.09 & 0.16 \\
\hline & Unsuccessful & $0.65^{* *}$ & $0.57^{*}$ & $0.83^{* *}$ & $0.76^{*}$ & $0.64^{*}$ & 0.20 & 0.29 \\
\hline \multirow{2}{*}{$\begin{array}{l}\text { Dribble } \\
\text { past }\end{array}$} & Successful & 0.05 & -0.43 & -0.25 & -0.36 & -0.30 & -0.10 & -0.21 \\
\hline & Unsuccessful & 0.07 & 0.07 & -0.16 & 0.02 & -0.25 & -0.01 & 0.02 \\
\hline \multirow{2}{*}{ Passing } & Successful & -0.28 & -0.44 & $-0.67^{* *}$ & $-0.54^{*}$ & -0.25 & 0.00 & -0.42 \\
\hline & Unsuccessful & 0.29 & 0.25 & 0.47 & 0.36 & 0.33 & 0.18 & 0.33 \\
\hline Assist & Successful & -0.21 & $-0.50^{*}$ & -0.35 & -0.29 & -0.21 & -0.17 & -0.24 \\
\hline \multicolumn{9}{|c|}{$\begin{array}{c}{ }^{*} p<0.05,{ }^{*} p<0.01, C o P_{d a p}: \text { dominant leg anterior-posterior sway, CoPdml: dominant leg medial-la } \\
\text { sway, CoPdvel: dominant leg sway velocity, CoPdvar: dominant leg sway average, CoPecml: both } 1 \\
\text { stance eyes closed medial-lateral sway, CoPecvel: both leg stance eyes closed sway velocity, } \\
\text { CoPecvar: both leg stance eyes closed sway average }\end{array}$} \\
\hline
\end{tabular}




\section{Discussion}

The main purpose of the present study was to determine the relationship between postural control variables and soccer specific technical variables, which has never been studied from this perspective. The main finding we observed was that the CoP variables for the dominant leg and eyes closed were correlated with success in performing soccer specific technical skills at varying degrees depending on the changes in SSG formats.

Although success in performing specific technical skills in a game is relative to athletes' technical levels for the specific skill, in all branches of sport, different levels of sensorimotor processes are required to perform branch-specific skills and protect from injuries (Bressel et al., 2007). Factors affecting coordination, range of motion and strength also have crucial effects on postural adaptation and balance. In addition, these factors include sensory information from motor responses originating from somatosensors and the visual and vestibular systems (Grigg, 2010; Palmieri et al., 2002). Postural adaptation and balance are important features for soccer players to set their body positions quickly, maintain them completely and perform perfectly their technical skills under challenging conditions such as sudden direction changes of the ball and distractions (slippery field, wind, etc.) caused among others, by different types of shoes designed for different types of surface (Evangelos et al., 2012) when engaging in physical tackles of the opponent during a soccer match. In our study, designed with respect to these assumptions, one of the hypotheses was that variables of postural control might be effective when athletes were standing through tackles and performing successfully. Indeed, particularly in 1:1 and 2:2 games that included fewer numbers of players and more tackles, the relationship found between better values of dominant leg CoP variables and increased winning skills in tackles supported our hypothesis (Tables 2, 3).

When athletes or sedentary subjects were given balance tests with eyes closed under normal conditions, balance losses increased with the effect of decreased information coming from visual stimuli and, therefore, the need for sensory and muscular data increased to maintain balance (Bronstein and Buckwell, 1997; Gill et al., 2001;
Turano et al., 1994). Similarly, when athletes encountered a tactile outside factor, they needed to benefit from the balance systems in muscles more to ensure postural control (Hahn et al., 1999). During SSGs in soccer, particularly with tackles that create more external perturbations such as contact with the opponent, it would be difficult to maintain balance under decreasing or disturbed sensory inputs (visual, vestibular and somatosensory). Under these circumstances, it has been claimed that another sensory system replaces the sensory system, which is unable to fully control balance (Horak et al., 1990b). It was also suggested that the success of the movement to be made could be correlated with the levels of use of one or more of these systems quickly and effectively (sensory adaptation). Likewise, in our study, the finding that the athletes who were more successful in the $\mathrm{CoPec}_{\mathrm{ec}}$ test applied with no visual input performed better in tackles could be interpreted as these athletes having higher levels of effective use of vestibular or somatosensory systems.

In addition, differences in latency responses induced by the lower and upper body muscles to pushing and pulling movements with the opponent during tackles (Winter, 1995) seem to be another factor that can explain success during tackles. Since effective factors during tackles that take place in a dynamic structure in SSGs cannot be standardized, the levels of force applied to different parts of the body and the direction of strength will differ for each tackle. Although automatic postural responses (Horak and Nashner, 1986a) made to correct complexities that occur in the body central mass appear 70-120 ms after spinal reflexes (30-50 ms) and before voluntary contractions (220-280 ms), muscular responses are considered to vary in time due to the differences in non-standardized external perturbations.

In the aforementioned study, it was reported that the latency response of posterior leg muscles was 45-60 ms when a $200 \mathrm{~N}$-force was applied to the upper body from an anterior direction, however, the findings of other studies revealed a longer latency response (80-100 ms) (Nashner, 1977; Winter, 1995). In addition, it has been suggested that latencies of $30 \mathrm{~ms}$ in the biceps muscles followed by $50 \mathrm{~ms}$ in the gastrocnemius occur in the responses of sudden 
body push forwards and latencies of approximately $40 \mathrm{~ms}$ in plantarflexor or dorsiflexor muscles in pullbacks. However, failure to determine the impulsive forces of external perturbations during tackles and their response times, which is essential to provide a clearer explanation, is a limitation of the present study.

Aside from the tackles that include intensive external perturbations during a soccer match, performing technical skills such as passing, shooting and dribbling past correctly under the pressure of an opponent, requires a standing-on-one-leg posture and stability of the non-dominant leg as well. With respect to these requirements, with the data obtained from measurements of the one-leg-standing posture, better assessments could be made for soccer specific postural control. Thus, in our study, statistical relationships were observed between postural control variables of the dominant leg (CoPdml, CoPdvel, CoPdvar, CoPecml, CoPecvel, and CoPecvar) and successful and unsuccessful dribbles, successful passes and goal passes in the 1:1, 2:2 and 3:3 games and between the variables of the non-dominant leg successful-unsuccessful shots and unsuccessful passes in the 2:2 and 3:3 games. Negative correlations may refer to a higher level of skill application during predetermined technique variables (determinant of better postural control levels as the $\mathrm{CoP}$ deviations were reduced), and vice versa. This results from the fact that, when performing technical skills that require complex motor structuring, especially under opponent pressure, good balance control (staticdynamic) is needed to perform motor movements at different levels fluently and correctly. The state of balance is revealed by the responses given to the coordination of vestibular, visual and somatosensory processes (Wikstrom et al., 2005) and with the feedback obtained from these sensors, in which necessary contractions are made to maintain postural stability (Nashner, 1982; Shumwaycook and Horak, 1986). This period, which has to be passed by minimizing disturbances to ensure perfection in movement precision and balance control, can be interpreted as a reason why the athletes, who obtained better results in postural control, performed technical variables better even under opponent pressure. Furthermore, previous studies revealed that the ability of balance, which can be improved through training, positively affected the levels of performance of branch specific technical skills (Evangelos et al., 2012; Nikolaos et al., 2012).

The results of our study show that higher postural control levels are among the important variables that influence success in performing technical skills required under opponent pressure and suddenly changing situations. Therefore, balance training used for injury prevention purposes before and during a season may have great contributions for coaches when they aim at improving branch specific skills and increasing their successful use in a game. However, a limitation of the current study is the small sample size. Therefore, replication studies with larger sample sizes should be conducted. Further studies to associate the effects of training designed for the development of postural control with the performance of technical variables used in the analysis of official matches will provide more valid data on the issue.

\section{Acknowledgements}

The author would like to thank Prof. Dr. Tuncay Varol and Dr. Serkan Özgür for their technical assistance in data collection.

\section{References}

Bressel E, Yonker JC, Kras J, Heath EM. Comparison of static and dynamic balance in female collegiate soccer, basketball, and gymnastics athletes. J Athl Train, 2007; 42(1): 42-46

Bronstein AM, Buckwell D. Automatic control of postural sway by visual motion parallax. Exp Brain Res, 1997; 113(2): 243-248

Casamichana D, Castellano J. Time-motion, heart rate, perceptual and motor behaviour demands in smallsides soccer games: Effects of pitch size. J Sports Sci, 2010; 28(14): 1615-1623

Castellano J, Casamichana D, Dellal A. Influence of Game Format and Number of Players on Heart Rate 
Responses and Physical Demands in Small-Sided Soccer Games. J Strength Cond Res, 2013; 27(5): 12951303

Daneshjoo A, Mokhtar AH, Rahnama N, Yusof A. The effects of comprehensive warm-up programs on proprioception, static and dynamic balance on male soccer players. PloS one, 2012; 7(12): e51568.

Davlin CD. Dynamic balance in high level athletes. Percept Mot Skills, 2004; 98(3 Pt 2): 1171-1176.

Dellal A, Owen A, Wong DP, Krustrup P, van Exsel M, Mallo J. Technical and physical demands of small vs. large sided games in relation to playing position in elite soccer. Hum Mov Sci, 2012; 31(4): 957-969 (a)

Dellal A, Varliette C, Owen A, Chirico EN, Pialoux V. Small-sided games versus interval training in amateur soccer players: effects on the aerobic capacity and the ability to perform intermittent exercises with changes of direction. J Strength Cond Res, 2012; 26(10): 2712-2720 (b)

Durnin J, Rahaman M. The assessment of the amount of fat in the human body from measurements of skinfold thickness. Br J Nutr, 1967; 21(03): 681-689

Evangelos B, Georgios K, Konstantinos A, Gissis I, Papadopoulos C, Aristomenis S. Proprioception and balance training can improve amateur soccer players' technical skills. J Phys Educ Sport, 2012; 12(1): 81

Gauffin H, Tropp H, Odenrick P. Effect of ankle disk training on postural control in patients with functional instability of the ankle joint. Int J Sports Med, 1988; 9(02): 141-144

Gerbino PG, Griffin ED, Zurakowski D. Comparison of standing balance between female collegiate dancers and soccer players. Gait \& Posture, 2007; 26(4): 501-507

Gill J, Allum JHJ, Carpenter MG, Held-Ziolkowska M, Adkin AL, Honegger F, Pierchala K. Trunk sway measures of postural stability during clinical balance tests: Effects of age. J Gerontol A Biol Sci Med Sci, 2001; 56(7): M438-M447

Grigg P. Peripheral neural mechanisms in proprioception. JSR, 2010; 3(1)

Hahn T, Foldspang A, Vestergaard E, Ingemann-Hansen T. One-leg standing balance and sports activity. Scand J Med Sci Sports, 1999; 9(1): 15-18

Hill-Haas SV, Dawson BT, Coutts AJ, Rowsell GJ. Physiological responses and time-motion characteristics of various small-sided soccer games in youth players. J Sports Sci, 2009; 27(1): 1-8

Horak FB, Nashner LM. Central Programming of Postural Movements - Adaptation to Altered SupportSurface Configurations. J Neurophysiol, 1986; 55(6): 1369-1381 (a)

Horak FB, Nashner LM, Diener HC. Postural Strategies Associated with Somatosensory and Vestibular Loss. Exp Brain Res, 1990; 82(1): 167-177 (b)

Hughes M, Franks I. Analysis of passing sequences, shots and goals in soccer. J Sports Sci, 2005; 23(5): 509514

Jeannerod M. The neural and behavioural organization of goal-directed movements. Clarendon Press/Oxford University Press; 1988

Jones S, Drust B. Physiological and technical demands of $4 \mathrm{v} 4$ and $8 \mathrm{v} 8$ games in elite youth soccer players. Kinesiology, 2007; 39(2): 150-156

Katis A, Kellis E. Effects of small-sided games on physical conditioning and performance in young soccer players. J Sports Sci Med, 2009; 8(3): 374-380

Kelly DA, Drust B. The effect of pitch dimensions on heart rate responses and technical demands of smallsided soccer games in elite players. J Sci Med Sport, 2009; 12(4): 475-479

Köklü Y, Asçi A, Koçak FÜ, Alemdaroglu U, Dündar U. Comparison of the physiological responses to different small-sided games in elite young soccer players. J Strength Cond Res, 2011; 25(6): 1522-1528

Massion J. Postural control systems in developmental perspective. Neurosci Biobehav Rev, 1998; 22(4): 465-472

Nashner L. Fixed patterns of rapid postural responses among leg muscles during stance. Exp Brain Res, 1977; 
30(1): 13-24

Nashner LM. Adaptation of Human Movement to Altered Environments. Trends Neurosci, 1982; 5(10): 358361

Nikolaos K, Evangelos B, Nikolaos A, Emmanouil K, Panagiotis K. The Effect of a Balance and Proprioception Training Program on Amateur Basketball Players' Passing Skills. J Phys Educ Sport, 2012; 12(3): 316

Paillard J. Motor and representational framing of space. Brain Spa, 1991; 163-182

Paillard T, Costes-Salon C, Lafont C, Dupui P. Are there differences in postural regulation according to the level of competition in judoists? Br J Sports Med, 2002; 36(4): 304-305

Paillard T, Noe F. Effect of expertise and visual contribution on postural control in soccer. Scand J Med Sci Sports, 2006; 16(5): 345-348

Paillard T, Noe F, Riviere T, Marion V, Montoya R, Dupui P. Postural performance and strategy in the unipedal stance of soccer players at different levels of competition. J Athl Train, 2006; 41(2): 172-176

Palmieri RM, Ingersoll CD, Stone MB, Krause BA. Center-of-pressure parameters used in the assessment of postural control. J Sport Rehab, 2002; 11(1): 51-66

Pintsaar A, Brynhildsen J, Tropp H. Postural corrections after standardised perturbations of single limb stance: Effect of training and orthotic devices in patients with ankle instability. Br J Sports Med, 1996; 30(2): 151-155

Shumwaycook A, Horak FB. Assessing the influence of sensory interaction on balance - suggestion from the field. Phys Ther, 1986; 66(10): 1548-1550

Siri WE. Body composition from fluid spaces and density: Analysis of methods. Lawrence Radiation Laboratory, University of California, Berkeley; 1956

Soderman K, Werner S, Pietila T, Engstrom B, Alfredson H. Balance board training: prevention of traumatic injuries of the lower extremities in female soccer players? A prospective randomized intervention study. Knee Surge Sports Traumatol Arthrosc, 2000; 8(6): 356-363

Turano K, Rubin GS, Herdman SJ, Chee E, Fried LP. Visual Stabilization of Posture in the Elderly - Fallers Vs Nonfallers. Optom Vis Sci, 1994; 71(12): 761-769

Vuillerme N, Danion F, Marin L, Boyadjian A, Prieur JM, Weise I, Nougier V. The effect of expertise in gymnastics on postural control. Neurosci Lett, 2001; 303(2): 83-86 (a)

Vuillerme N, Teasdale N, Nougier V. The effect of expertise in gymnastics on proprioceptive sensory integration in human subjects. Neurosci Lett, 2001; 311(2): 73-76 (b)

Wikstrom EA, Tillman MD, Smith AN, Borsa PA. A new force-plate technology measure of dynamic postural stability: The dynamic postural stability index. J Athl Train, 2005; 40(4): 305-309

Winter DA. Human balance and posture control during standing and walking. Gait $\mathcal{E}$ Posture, 1995; 3(4): 193-214

\section{Corresponding author:}

\section{Dr. Faik VURAL}

Division of Sport Health Sciences, Ege University School of Physical Education and Sport, 35100 Bornova-Izmir, TURKEY

Phone m.: +90.555.4822538; Phone: +90.232 .3425714$

Fax: +90.232 .3399000$

E-mail: faik.vural@ege.edu.tr, faik.vural1@gmail.com 